\title{
44332 - EFFECTS OF LUBRICANTS ON THE STYLET REMOVAL FROM ENDOTRACHEAL TUBES
}

\author{
Hung Christopher, Dalhousie University, Halifax, NS, Canada; \\ David Hung, Dalhousie University; \\ Kwesi Kwofie, Dalhousie University; \\ A Guzzo, University of Toronto; \\ OR Hung, Dalhousie University;
}

\section{INTRODUCTION:}

Lubrication of a stylet is commonly employed to facilitate its removal following the placement of the endotracheal tube (ETT). However, presently there is no information about the effectiveness of these lubricants. The goal of this study is to determine the amount of effort required to remove a stylet from the ETT after the application of a variety of commonly used lubricants.

\section{METHODS:}

This QA study was approved by our institution. A total of 210 new stylets and ETTs were used. Each new stylet was loaded into the ETT, with or without lubrication, with a 90 bend at $7 \mathrm{~cm}$ from the distal tip. The lubricants used were: sterile water $(\mathrm{W})$, silicone fluid (S), Xylocaine spray (X), Xylocaine Gel (G), AMG gel (A), Lacrilube (L), and none (N). Work analysis was completed at 0, 5, and 30 mins, and at 1, 3 and 24 hours after the stylet was loaded into the ETT. Five stylets and ETTs were used for each lubricant and at each time point.

\section{RESULTS:}

The Table summarizes the work (mean \pm SD in joules) required to retract the stylet $5 \mathrm{~cm}$ away from the ETT at different time points. In general, more work was required to retract the stylet without the lubricants $(\mathrm{N})$ with large variabilities. Silicone fluid $(\mathrm{S})$ required the least work and did not appear to change with time. However, water appeared to be as effective as the other lubricants. The effectiveness of the lubrication appeared to deteriorate over time with $\mathrm{X}$ and $\mathrm{G}$.

\section{DISCUSSION:}

The data from this study demonstrate that the most effective lubricant for ETT stylet withdrawal is (S), with (W) being the best studied alternative. This suggests that other commonly employed ETT stylet lubricants in the typical operating room (which may be quite costly to the hospital) may not be necessary. With (W) performing better in our studies and with cheaper costs than most of the other tested lubricants in nearly all time points, perhaps this could be considered the most practical and cost-effective ETT-stylet lubricant. 


\section{Table:}

Table: The mean $\pm \mathrm{SD}$ work (in joules) required to retract the stylet $5 \mathrm{~cm}$ from the ETT with a $90^{\circ}$ bend at different time points.

\begin{tabular}{|c|c|c|c|c|c|c|c|}
\hline $\begin{array}{l}\text { Time } \\
\text { (min) }\end{array}$ & $\mathrm{N}$ & W & S & $\mathrm{X}$ & G & A & L \\
\hline 0 & $0.94 \pm 0.28$ & $0.53 \pm 0.09^{*}$ & $0.43 \pm 0.10^{*}$ & $0.68 \pm 0.09$ & $0.60 \pm 0.15^{*}$ & $0.57 \pm 0.07^{*}$ & $0.68 \pm 0.07$ \\
\hline 5 & $0.69 \pm 0.37$ & $0.57 \pm 0.17$ & $0.38 \pm 0.04$ & $0.54 \pm 0.10$ & $0.67 \pm 0.11$ & $0.62 \pm 0.18$ & $0.71 \pm 0.05$ \\
\hline 30 & $0.62 \pm 0.10$ & $0.54 \pm 0.11$ & $0.43 \pm 0.05^{*}$ & $0.65 \pm 0.02^{\S}$ & $0.65 \pm 0.04$ & $0.56 \pm 0.04$ & $0.57 \pm 0.07$ \\
\hline 60 & $0.70 \pm 0.12$ & $0.57 \pm 0.09$ & $0.42 \pm 0.06^{*}$ & $0.76 \pm 0.07$ & $0.71 \pm 0.03$ & $0.59 \pm 0.09$ & $0.67 \pm 0.05$ \\
\hline 180 & $0.76 \pm 0.37$ & $0.63 \pm 0.08$ & $0.43 \pm 0.05^{*}$ & $0.82 \pm 0.12$ & $0.56 \pm 0.07$ & $0.61 \pm 0.02$ & $0.64 \pm 0.07$ \\
\hline 1440 & $0.77 \pm 0.24$ & $0.69 \pm 0.11$ & $0.49 \pm 0.01^{*}$ & $0.90 \pm 0.18^{\S}$ & $1.00 \pm 0.09^{\xi}$ & $0.68 \pm 0.07$ & $0.67 \pm 0.07$ \\
\hline
\end{tabular}

